ppi $201502 Z U 4645$

Esta publicación científica en formato digital es continuidad de la revista impresa ISSN-Versión Impresa 0798-1406 / ISSN-Versión on line 2542-3185Depósito legal pp $197402 Z$ U34

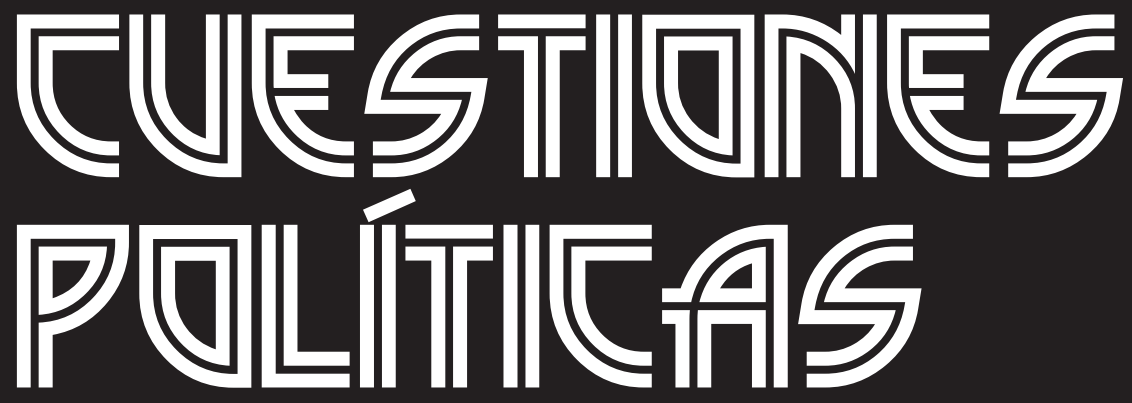

Instituto de Estudios Políticos y Derecho Público "Dr. Humberto J. La Roche" de la Facultad de Ciencias Jurídicas y Políticas de la Universidad del Zulia Maracaibo, Venezuela
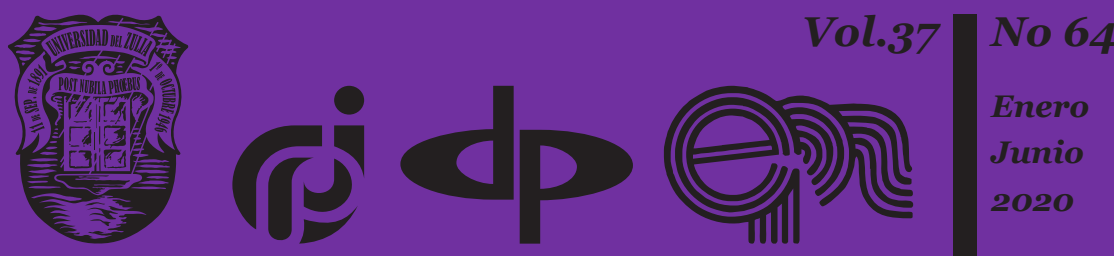


\title{
Desmitificando las ideas económicas de Adam Smith *
}

\author{
Leonardo Favio Osorio Bohórquez **
}

\section{Resumen}

El objetivo de este trabajo es analizar las obras de Adam Smith sobre "La teoría de los sentimientos morales" y "La Riqueza de las naciones", de esa forma se pueden entender sus dos facetas, la de economista y filósofo, con el fin de desmontar toda una serie de mitos sobre sus planteamientos teóricos. La tesis sobre el egoísmo y materialismo de los hombres, la idea de la mano invisible, del papel del Estado en la sociedad, entre otras afirmaciones, han sido mal interpretadas sobre todo por las corrientes marxistassocialistas y estatistas. De ahí la importancia de releer las obras de Adam Smith sin fines maniqueos, para realmente explicar los fundamentos básicos de sus ideas. Las dos obras de Smith no son en lo absoluto contradictorias sino complementarias, por eso la importancia de leerlas de forma paralela. Se utilizan los métodos analítico-sintético y analógico-comparativo para la realización de la investigación, por medio de una revisión bibliográfica. Se concluye que Smith siempre argumentó la importancia de buscar el bienestar individual y colectivo como único medio para lograr la prosperidad de las mayorías.

Palabras clave: Adam Smith; liberalismo; Teoría de los sentimientos morales; Riqueza de las naciones; filosofía política.

Este trabajo es un avance del proyecto de tesis doctoral titulado: "Poder y Negocios en el proceso de consolidación del Estado liberal venezolano. Caso Zulia 1908-1936”. Tesis presentada y defendida en el Doctorado de Ciencias Humanas en la Universidad del Zulia en el año 2019.

** Universidad del Zulia. Centro de Estudios Históricos. Email: Leonardofavio87@gmail.com. 


\title{
Demystifying Adam Smith’s economic ideas
}

\begin{abstract}
The objective of this work is to analyze the Adam Smith's works on "The Theory of Moral Sentiments" and "The Wealth of Nations", in this way his two facets, that of economist and philosopher, can be understood, with the aim of dismantle a whole series of myths about his theoretical approaches. The thesis on the egoism and materialism of men, the idea of the invisible hand, of the role of the state in society, among other claims, have been misinterpreted mainly by marxist-socialist and statist currents. Hence the importance of rereading the Adam Smith's works without fiddling, to really explain the basic foundations of his ideas. Smith's two works are not at all contradictory but complementary: therefore, the importance of reading them in parallel. The analytical-synthetic and analog-comparative methods are used to carry out the research through a bibliographic review. It is concluded that Smith always argued the importance of seeking individual and collective well-being as the only means to achieve the prosperity of the majorities.
\end{abstract}

Key words: Adam Smith; liberalism; Theory of Moral Sentiments; Wealth of Nations; political philosophy.

\section{Introducción}

El objetivo de este trabajo es analizar las obras de Adam Smith sobre la "Teoría de los sentimientos morales" e "Investigación sobre la naturaleza y causas de la riqueza de las naciones", de esa forma se pueden entender sus dos facetas: la de economista y la de filósofo, para desmontar toda una serie de mitos sobre sus ideas económicas.

Smith ha sido uno de los economistas más influyentes, incluso en la actualidad, aunque muchas de sus tesis no sean originales, logra sistematizar toda una serie de planteamientos existentes para su época, pero su trabajo ha sido mal interpretado en parte por quienes no comprenden bien sus ideas, y por aquellas corrientes socialistas e intervencionistas que satanizan las economías de libre mercado.

El nombre de liberalismo económico empieza a usarse sobre todo a partir del siglo XIX, tiempo después de escrita la obra de Adam Smith, aunque sus argumentos se consideran clave para explicar cómo debe funcionar una economía liberal. Para muchos Smith es el padre de la economía, pero 
tal vez Richard Cantillon (1950) fue más innovador en sus planteamientos expuestos en su libro sobre "La naturaleza del comercio", pero Smith también es un autor fundamental que sintetiza muchas ideas dispersas, y su obra tiene mayor impacto en el mundo académico.

Por eso vale la pena aclarar muchos de sus planteamientos. Adam Smith en su obra sobre los sentimientos morales, expresa la idea de que el hombre es un ser social que también busca el beneficio de los otros individuos. La virtud y el deseo de bienestar del prójimo son principios importantes expresados en su obra.

Por consiguiente, la reacción de Smith ante el mercantilismo expuesta en su obra La riqueza de las naciones, en la que se observa su lucha ante un sistema que asignaba privilegios solo a una minoría en desmérito de los demás individuos. El libre comercio favorece no solo a los comerciantes sino también a los consumidores y la sociedad en general.

De ahí, sus ideas deben ser adecuadamente comprendidas para evitar caer en tergiversaciones. Analizar el texto sobre Los sentimientos morales permite comprender mucho mejor los argumentos de Smith con respecto a la economía en general y, en particular, su visión antropológica del hombre.

Para analizar sus dos obras se utilizan los métodos analítico-sintético y analógico-comparativo. Releer a Smith es de vital importancia en la actualidad, porque la libertad económica sufre cuestionamientos constantes, $\mathrm{y}$ han resurgido las tesis a favor del intervencionismo de los Estados. Por eso es que la realidad política ha condicionado cada vez más la economía, situación que demanda analizar ambas realidades de forma articulada.

Sin lugar a dudas se ha malinterpretado la idea de Smith sobre el papel del Estado en la economía y la llamada mano invisible del mercado, cuando en realidad el autor fue muy exigente en señalar que esto debía tenerse como referencia para la asignación de los recursos, pero los agentes productivos debían ser sometidos a una eficiente y severa supervisión por parte de las autoridades públicas.

Portanto, hayquedeslastrartodauna seriedeprejuiciosytergiversaciones sobre las obras de Smith. A pesar de existir varias investigaciones que estudian las dos facetas de Smith en sus libros, en este trabajo particular se analizan tópicos particulares referidos al comercio, al papel del Estado en la economía y la visión moral y antropológica de los hombres en sociedad. 


\section{Desmontando mitos sobre las ideas de Smith y las funciones de los Estados}

Uno de los puntos clave en la obra de los economistas ha sido cuál debe ser el papel del Estado en la economía. En la actualidad ha habido un gran resurgir de las tesis intervencionistas en materia económica, tales como el keynesianismo, sobre todo debido a las grandes crisis como la acontecida en el 2008 en Estados Unidos. El problema es que los políticos con la excusa de resolver crisis, han abusado de esa función del Estado y pasaron a utilizar el gasto fiscal en forma irresponsable, ${ }^{3}$ incurriendo en déficit no sólo para estimular la demanda sino para cautivar votos, es decir, con fines clientelares. ${ }^{4}$

Ante esos peligros es que Smith planteó en su momento la necesidad de limitar la acción de los gobernantes, pero también afirmó la importancia de mantener una supervisión por parte de las autoridades y algunas regulaciones. En su texto La teoría sobre los sentimientos morales, por ser un libro de filosofía, no aborda directamente el papel del Estado, aunque también hace afirmaciones que denotan las limitantes de los gobernantes para interferir en la vida de las personas.

Lógicamente, donde se argumenta más explícitamente la tesis sobre el Estado es sin lugar a dudas en el libro Investigación sobre el origen y causas de las riquezas de las naciones, publicado en 1776. Muchos de los planteamientos eran reflejo de la realidad que acontecía en la Inglaterra del siglo XVIII. Pero tuvo el mérito de ser uno de los primeros autores en sistematizar de manera coherente los puntos fundamentales de la economía de libre concurrencia.

La obra de Smith fue una reacción al mercantilismo y a la función que le atribuía al Estado, por eso cuando explica las funciones del gobierno plantea que este debe amparar la libre competencia y no otorgar privilegios a ningún individuo o grupo económico en particular, y debiera actuar en todo caso, para destruir toda posición monopolista, ya fuera del capital o del trabajo, que los hombres hubieran obtenido por medio de una acción concertada. La conservación de la libre competencia era el principal deber de la política económica (Smith, 1979).

Las ideas de Smith eran una crítica al mercantilismo, especialmente a los monopolios establecidos por el Estado a los individuos con vínculos

3 Henry Hazlitt critica las tesis keynesianas, demuestra cómo lo mejor que el Estado puede hacer para reducir la gravedad de los problemas ante el paro y la recesión, es permitir y fomentar el funcionamiento del sistema de mercado libre (Hazlitt, 1961).

El aumento del gasto público se observa sobe todo cuando se está en presencia de años electorales en diferentes países. 
políticos. ${ }^{5}$ Se trataba de que cada quien recibiera su recompensa en función de su esfuerzo personal, innovación y méritos, y no por medio de los favores de los gobiernos.

Por lo tanto, bajo ningún concepto se puede argumentar que las economías de libre competencia favorecen los monopolios. Como afirma Mises, el auge de los monopolios, más que producto de la acción del libre mercado, se debió a la intervención del Estado para asignar privilegios: "El hablar de capitalismo monopolista es la mayor de las hipocresías. Más correcto resultaría aludir al estatismo o intervencionismo monopolista" (Von Mises, 1986: 990).

Por eso Smith siempre criticó los monopolios amparados por el Estado. Similares planteamientos en contra de la asignación de privilegios por parte del Estado fueron planteados en su Teoría sobre los sentimientos morales:

Aquellos príncipes que con la mayor profusión han colmado de riquezas, poder y honores a sus favoritos, pocas veces han provocado ese grado de adhesión a sus personas, que con frecuencia han disfrutado otros que fueron más parcos en sus favores. La bien intencionada, pero poco juiciosa, prodigalidad de Jacobo I de Gran Bretaña, al parecer no atrajo a nadie a su persona, y este príncipe, a pesar de su índole sociable e inocua por lo visto vivió y murió sin un solo amigo (Smith, 1978: 84).

Acá Smith explica los favores dados durante la época de Jacobo I en Inglaterra. Si bien en su obra sobre Los sentimientos morales se explica que eso no garantiza la simpatía de los demás individuos, sino que más bien es contraporducente. Era un primer planteamiento en contra de privilegios estatales.

Esta idea en La riqueza de las naciones, como ya se expresó, fue duramente atacada en el plano económico. Según Smith, el Estado debía cumplir tres funciones básicas: justicia, seguridad y obras públicas (Smith, 1979). Las leyes debían permitir el funcionamiento de los mercados y garantizar la libertad de las personas. Una institucionalidad sólida es lo que da garantía a los capitales y a los individuos.

Los gobiernos debían construir además diferentes vías de comunicación como un medio para lograr el progreso económico de los individuos y de las naciones. De igual forma, debían garantizar la seguridad, tanto a la integridad física y personal como a los bienes. La propiedad privada es un derecho inquebrantable en los Estados modernos.

5 Adam Smith fue un crítico de las medidas de política comercial mercantilistas en razón de que se prestaban para la concesión de privilegios y monopolios por el Estado a los particulares en la Inglaterra del siglo XVIII, en detrimento de los consumidores y los productores eficientes. Su obra tuvo gran acogida precisamente por los grupos mercantiles que deseaban participar dentro de una economía de libre empresa que les diera las mismas oportunidades a todos los agentes económicos para así demostrar sus capacidades competitivas. 
Por lo tanto, Smith afirmaba que el Estado debe amparar las propiedades de los individuos, el gobierno civil era instituido para asegurar la propiedad (Smith, 1979). Se ponía límites a la acción del Estado, reduciendo sus competencias a áreas específicas y bien delimitadas. La producción de riqueza era competencia de los individuos y no del Estado, y era el mercado el encargado de redistribuirla con base en los méritos personales.

En La riqueza de las naciones, Smith limitaba la acción del Estado a ámbitos específicos, y en su Teoría sobre los sentimientos morales también exponía la necesidad de cuidar las funciones del gobierno:

La índole de los hombres, así como los artefactos o las instituciones del gobierno civil, pueden servir o para fomentar o para perturbar la felicidad, tanto del individuo como de la sociedad. El carácter prudente, equitativo, diligente, resuelto y sobrio, promete prosperidad y satisfacción, tanto para la persona como para los que están en relación con ella. Por el contrario, la arrebatada, la insolente, la perezosa, afeminada y voluptuosa, presagia la ruina de los individuos y la desgracia a todos con los que de él tenga trato (Smith, 1978: 122).

Aquí se ve una clara advertencia a las funciones o prudencia con la que debe actuar el gobierno civil, que puede generar la ruina de los individuos si no está imbuido de ciertos valores fundamentales. Es evidente también la importancia de las virtudes individuales, que permiten una sana convivencia social para la prosperidad. Por otro lado, los vicios solo ayudan a perturbar el orden social.

El Estado debía estar formado por los individuos más capaces para ejercer funciones de gobierno, que hayan demostrado tener las virtudes apropiadas. Smith hace fuerte hincapié en las virtudes de los gobernantes en su obra de Los sentimientos morales:

¿Acaso puede existir otra institución de gobierno más adecuada para fomentar la felicidad humana que la preponderancia de la sabiduría y la virtud? Todo gobierno no es sino un remedio imperfecto a la falta de éstas. Por tanto, la belleza que pueda corresponder al gobierno civil a causa de su utilidad, necesariamente deberá corresponder en mucho mayor grado a la sabiduría y la virtud. Por lo contrario, ¿qué otro sistema político puede ser más ruinoso y destructivo que los vicios de los hombres? La única causa de los efectos fatales que acarrea un mal gobierno, es que no imparte suficiente protección contra los daños a que da lugar la maldad de los hombres (Smith, 1978: 123).

Smith señala nuevamente la importancia de un gobierno virtuoso. Esos planteamientos son similares a los establecidos por Platón en La república, cuando hacía énfasis en la virtud y sabiduría de los gobernantes. La sabiduría se expresa en la formación intelectual, y la virtud está asociada al cumplimento de las leyes y normativas sociales. Dentro del Estado debían superarse los vicios asociados a la corrupción, para garantizar el cumplimiento de la ley y la igualdad de oportunidades para todos. 
Otro elemento importante es la protección que los gobernantes debían brindar a sus ciudadanos, bien establecieron los filósofos políticos clásicos, como Hobbes, que la seguridad es uno de los fines primordiales del Estado, así se elimina la guerra de todos contra todos (Hobbes, 1980). Por eso, los gobernantes debían mantener su utilidad como garantes de la paz. Las autoridades debían garantizar a la ciudadanía el cumplimento de sus funciones y no excederse en sus competencias. Similares argumentos habían sido planteados por John Locke con respecto al gobierno civil, sobre la necesidad de ponerle límites, y de resistirse a todo intento por parte de los gobernantes de trasgredir los derechos de los individuos, incluso teniendo los individuos el derecho a retirar su confianza al gobernante y rebelarse cuando éste no cumple con su función (Locke, 1991).

Por eso el gobierno asumía funciones como una institución garante de los derechos individuales contractuales. El mismo Estado debía cumplir las leyes, de otra forma los individuos están facultados para desobedecer sus instrucciones en caso de que se pretenda violentar los pactos políticos.

Eso no implicaba una tesis a favor de la anarquía. De hecho, Smith fue muy explícito en la importancia de una eficiente y transparente administración de la justicia, en una severa supervisión. El cumplimiento de los contratos es de vital importancia, también así el pago de los impuestos, el no acatamiento de esas normativas acarrea fuertes penas, incluso con la cárcel.

Dentro de esa supervisión, es otro mito lo de la muy mal entendida mano invisible del mercado, que será explicada más adelante. Smith planteó la necesidad de ciertas regulaciones por parte del Estado en situaciones de crisis económica (Smith, 1979). Pero esa intervención debe ser para garantizar el cabal funcionamiento del mercado y no para sustituirlo.

Se pensaba que la acción del gobierno lejos de ayudar a solventar las crisis, solo las empeoraría con políticas que afectaban el capital privado. El Estrado entonces debía mantener ciertos niveles de supervisión y regulación solamente para garantizar los principios fundamentales de la libertad económica.

\section{Adam Smith y la tesis sobre el comercio}

Las ideas planteadas por Smith básicamente defendían el libre juego entre la oferta y la demanda (Smith, 1979). La frase laissez faire, laissez passer es una expresión francesa que significa «dejen hacer, dejen pasar», expresa precisamente esa idea de dar libertades a la producción, comercio y consumo. Si bien la frase viene de los fisiócratas franceses, cuyo principal 
expositor es Quesnay, quien fundamentaba la riqueza en la explotación de la tierra, se impone en el ámbito económico el desarrollo de la industria y la manufactura promovido por los ingleses. Por lo demás, se abogaba por un comercio libre internacionalmente, liberado de las barreras arancelarias y los proteccionismos practicados comúnmente por las monarquías europeas, sobre todo durante el predominio de las ideas mercantilistas.

Las altas barreras arancelarias eran para encarecer las importaciones y favorecer la producción local. Pero según Smith, las naciones debían especializarse en aquellas industrias más eficientes que les permitiera resistir los efectos de la competencia y, en consecuencia, abandonar aquellas áreas de la economía sin capacidad competitiva (Smith, 1979).

Atrás se dejaba la obsesión de la economía mercantilista por lograr una balanza comercial positiva, se pensaba que todas las naciones se beneficiaban del comercio internacional (Smith, 2002). Más tarde los marxistas atacarían la tesis del libre comercio y, hoy en día, la han retomado con gran fuerza al plantear la idea de que solo se benefician del comercio los países más desarrollados, a costa de las débiles economías del llamado "tercer mundo".

Tales ideas son desarrolladas por autores como Samir Amin (2009), e incluso por economistas que están a favor del intervencionismo como Stiglitz en su texto sobre "El comercio justo" (Stiglitz, 2007). En contraposición a esos planteamientos, Smith planteaba las ventajas del comercio internacional como palanca para el crecimiento económico general de los países.

La promesa de la economía de mercado era lograr progreso, como una premisa base para conseguir la modernización de una nación. Fueron ideas innovadoras, a diferencia de los modelos económicos precedentes, como en la época feudal o esclavista, que no tenían esa noción del progreso.

El crecimiento económico, o como se conocería más comúnmente después con el nombre de desarrollo, fue concebido de acuerdo a los criterios de la Revolución Industrial como la capacidad técnica de elevar los niveles de producción, por medio del uso de la ciencia y la tecnología capaces de incrementar los niveles de eficiencia y eficacia de la productividad.

Smith esperaba también que la división del trabajo ayudara a la especialización y la innovación, necesarias para el desarrollo de las industrias con fines competitivos, para comercializar con más éxito la producción (Smith, 1979). Algunos consideran contradictorio desde una visión sesgada, el hecho de que Smith, a pesar de incentivar el libre comercio, haya ocupado un cargo como director de aduana. Smith fue nombrado director de aduana de Edimburgo en 1778, puesto que desempeñó hasta su muerte, el 17 de julio de 1790 , a causa de una enfermedad. 


\section{Desmitificando las ideas económicas de Adam Smith}

Aunque Smith abogaba por el libre comercio, nunca planteó el hecho de no cobrar impuestos. De hecho, desarrolló una teoría sobre la política tributaria. Smith argumentaba que los impuestos debían ser bajos para incentivar la actividad económica. Efectivamente, llegó a afirmar que los altos impuestos podían incitar al contrabando de mercancías (Smith, 1979).

Como se ha explicado, las ideas económicas propuestas por Smith no implicaban la ausencia de fiscalizaciones por parte de las autoridades, como se ha malinterpretado. El comercio tampoco debe implicar un modo de explotación, por lo que, en su tesis sobre los sentimientos morales argumenta sobre lo pragmático de las relaciones comerciales, pero también de la necesidad de establecer lazos afectivos entre los miembros de una sociedad:

Una sociedad de personas puede subsistir, como la de comerciantes, en razón de la utilidad mutua, sin ningún amor o afecto mutuo (...) por un intercambio mercenario. Pero la sociedad no puede subsistir entre quienes están constantemente prestos a herir a los otros (Smith, 1978: 2).

Entonces, no se pretende promover la explotación ni acabar con los otros competidores para vender los productos, se trata de favorecer a las industrias eficientes, por eso se combate el proteccionismo a las empresas ineficientes como bien explica Murray Rothbard:

El Proteccionismo simplemente declara que los consumidores, al igual que la prosperidad general, han de resultar perjudicados para conferir un privilegio especial permanente a grupos de productores menos eficientes, a expensas de las empresas más competentes y de los consumidores. Pero es un tipo de rescate particularmente destructivo, porque encadena permanentemente al comercio bajo el manto del patriotismo (Rothbard, 2006: 333-332).

Al final, el proteccionismo y las barreras arancelarias perjudican el progreso de las naciones, con la excusa de proteger la producción de empresas nacionales ineficientes incapaces de competir en un mercado libre. Esas tesis proteccionistas vienen de la época mercantilista. En La riqueza de las naciones, Smith expresa que fue el mercantilismo quien pretendió enseñar a los Estados que su interés consiste en arruinar a todos sus vecinos. El comercio, que debería ser entre las naciones como entre los individuos, es decir: un lazo de unión y amistad, se ha vuelto un campo fértil para el desacuerdo y la animosidad (Smith, 1979).

Esas ideas expresadas por Smith en La riqueza de las naciones demuestran que era realmente el mercantilismo quien asumía el comercio entre las naciones como una política de guerra y confrontación; el libre mercado debía permitir la prosperidad de todas las naciones. Lamentablemente, durante las guerras mundiales también se llevó a cabo una política de rivalidad comercial entre los países que dejaron de lado el liberalismo de libre concurrencia. 
Eso dio lugar a la aplicación de políticas keynesianas donde el Estado invierte en obras públicas e incurre en déficit fiscal, con el fin de elevar el gasto e incentivar el consumo para reactivar las economías. Las afirmaciones hechas por Smith en sus obras demuestran que, si bien la economía funciona bajo una lógica pragmática para ayudar a la prosperidad de los negocios, también es cierto que se necesita la concordia entre los individuos. La competencia entonces siempre implica cooperación.

\section{El mito sobre el egoísmo de los hombres y la mano invisible del mercado}

A la obra de Smith en particular, y al modelo liberal-capitalista en general, siempre se les ha condenado por promover la desigualdad, el egoísmo y la explotación entre los hombres. Se piensa que es un sistema que solo busca favorecer a los ricos y carece de toda ética. Estas tesis han sido planteadas principalmente por las corrientes marxistas-socialistas como se ha afirmado.

Por eso, como expresa Popper, buena parte de la crítica que se ha hecho al capitalismo, más allá de sus fundamentos económicos, en realidad es una crítica moral a sus principios básicos porque supuestamente promueve la injusticia y la desigualdad (Popper, 2010). Se asume que la pobreza de las grandes mayorías es debida a la explotación de la burguesía.

El marxismo ha sido muy exitoso en responsabilizar al libre mercado de buena parte de los males de la humanidad, debido a su "ausencia de moralidad" por el deseo de obtener ganancias. Una de las citas clásicas y que han sido de las más mal interpretadas y manipuladas sobre la tesis de Adam Smith, es la de la mano invisible del mercado.

Leyendo con cuidado La riqueza de las naciones y la Teoría de los sentimientos morales, se evidencia cómo Smith no planteó realmente una visión individualista y egoísta del hombre, siempre propuso la conciliación entre el interés individual con el de la sociedad. Incluso la tesis de la mano invisible bien lo establece:

Ninguno se propone, por lo general, promover el interés público ni sabe hasta qué punto lo promueve. Cuando prefiere la actividad económica de su país a la extranjera, únicamente considera su seguridad (...) pero en este caso como en muchos otros, es conducido por una mano invisible a promover un fin que no entraba en sus intenciones. Mas no implica mal alguno para la sociedad que tal fin no entre a formar parte de sus propósitos, pues al perseguir su propio interés, promueve el de la sociedad de una manera más efectiva que si esto entrara en sus designios (Smith, 1979:402). 
A pesar de que se interpreta esa frase como el deseo egoísta de los hombres de lograr siempre su propio beneficio, Smith nunca planteó la indiferencia de los hombres ante las necesidades ajenas. Se trataba era de crear un sistema que funcionara eficazmente en el plano económico. Era una advertencia de que el Estado no debía direccionar las acciones de los hombres.

De ahí la frase de que al perseguir el interés individual se favorece el de la sociedad, de forma más eficaz que si fuera ese su primer objetivo. El Estado, al intervenir queriendo "favorecer a las mayorías", muchas veces terminaba perjudicando a la economía y la sociedad en general. Por eso Smith afirma: "No son muchas las cosas buenas que vemos ejecutadas por aquellos que presumen de servir al interés público" (Smith, 1979: 402). Ideas a favor del interés particular se expresan en otra frase como la de: No es por la benevolencia del carnicero, del cervecero y del panadero que podemos contar con nuestra cena, sino por su propio interés (Smith, 1979).

Sin embargo, esto no debe tomarse como la idea del desinterés del individuo hacia el bienestar de la sociedad. Lo que plantea Smith es la no contradicción entre el interés individual con el colectivo. Por eso, como expresa Ángel Muñoz: "el hombre smithiano no pierde su naturaleza social al dejar actuar libremente su ser, ya que sin él proponérselo y como guiado por una mano invisible es capaz de procurar la felicidad para sí como para los demás" (Muñoz, 2005: 158-159).

Esa sería la interpretación correcta de la frase de la mano invisible de Smith, analizada en el adecuado contexto de su obra. La economía es un orden espontáneo donde todos pueden verse favorecidos en la realización de sus intereses sin la necesidad de ser guiados por fuerzas externas como el Estado. También afirma que no puede haber una sociedad floreciente y feliz cuando la mayor parte de sus miembros son pobres y desdichados (Smith, 1979).

Esa frase evidencia que existía una preocupación por el bienestar general de la sociedad en el texto de Smith. También hay una cuestión pragmática, era importante que existiera una sociedad próspera en lo económico para poder absorber la creciente producción industrial. A pesar de que la economía de mercado se pensaba iba en beneficio del sector mercantil, ningún otro modelo económico permitió tan altos niveles de capitalización de la clase trabajadora en general, al elevar considerablemente la renta per cápita y el Producto Interno Bruto de los países.

Para sostener los elevados niveles de productividad era necesario que existiera una población con suficiente capacidad económica para consumir la nueva producción industrial. Durante le Revolución Industrial se creó el principio de producir en masa y vender a bajos costos, con el fin de hacer más competitivos los productos en los mercados locales e internacionales. 
La misma dinámica del mercado, y no la benevolencia de los comerciantes como planteó Smith, hicieron que se mejoraran las condiciones de vida de la sociedad en general.

Marx había pronosticado el fin del capitalismo debido a la incapacidad de la clase trabajadora de absorber la creciente producción capitalista, lo que conllevaría al paro y la recesión económica. La realidad es que es en las economías ineficientes, donde no existen mercados libres, donde se vende a costos inaccesibles para la mayoría de la población.

Los altos niveles de capital y productividad elevan no solo las utilidades de los empresarios, sino también la capacidad de ahorro y consumo de la población. Por consiguiente, las tesis del liberalismo demostraron la posibilidad de generar prosperidad con beneficios para las mayorías, sobre todo en aquellas naciones donde hay instituciones transparentes y funciona el libre mercado por lo menos medianamente, como afirmó Smith.

Por tanto, no hay contradicciones en los textos de Smith, lo que hay son malas lecturas y frases sueltas no contextualizadas con la generalidad de sus planteamientos. Por eso, en su Teoría sobre los sentimientos morales establece que el hombre no puede ser un individuo indiferente ante la suerte de los demás:

\footnotetext{
Por más egoísta que quiera suponerse al hombre, evidentemente hay algunos elementos en su naturaleza que lo hacen interesarse en la suerte de los otros de tal modo, que la felicidad de éstos le es necesaria, aunque de ello nada obtenga, a no ser el placer de presenciarla. De esta naturaleza es la lástima o compasión, emoción que experimentamos ante la miseria ajena... (Smith, 1978: 31).
}

Las tesis de Smith, no plantean una competencia que busque acabar con los otros oferentes. Se reconoce el hecho, como es lógico, de que cada individuo busca su interés personal (esto no lo vuelve malvado), pero eso no implica ser indiferente ante las necesidades de los demás.

Al fin de cuentas un empresario es exitoso porque logra satisfacer las necesidades de los consumidores. La libertad para producir y vender facilita la satisfacción de la demanda. De esa manera, "los derechos de propiedad surgen de manera espontánea producto de la división del trabajo en grupos humanos muy ancestrales y que apoyados en ellos desarrollamos los juegos de no-suma cero que conducen a las compleja sociedades que hemos construido (Fischer, 2001: 153). Todas esas dinámicas llevan a la cooperación y la prosperidad con base en la satisfacción del interés propio y ajeno.

A partir de las ideas expresadas en su Teoría de los sentimientos morales y en La Riqueza de las naciones, algunos autores argumentan que surge un problema epistemológico entre su visión como filósofo y como economista. Pero, como bien afirman José Pena y José Sánchez, no 
existe tal contradicción: "En realidad, puede comprobarse que existen muy importantes analogías entre la configuración social propuesta en la TSM y la armonía del mercado de la RN, hasta el punto de ser parte de un mismo paradigma" (Pena, 2007: 98).

No se pueden contraponer dos versiones de Smith sobre su visión del individuo y la sociedad. El principio de la simpatía expresado en su Teoría de los sentimientos morales es compatible con sus tesis económicas en $\mathrm{La}$ riqueza de las naciones:

La simpatía es perfectamente compatible con el interés particular y tanto en la TSM como en la RN subsiste el mismo modelo humano. En última instancia, tomando como referencia la noción smithiana de simpatía es posible una corrección del paradigma tradicional en Economía y se puede imbricar tanto la ética y los comportamientos prosociales como el interés particular en el proceso de toma de decisiones. En otras palabras, el sistema económico condiciona la moral $\mathrm{y}$, a su vez, la moral es determinante del funcionamiento del sistema económico (Pena y Sánchez, 2007: 100).

Como plantean los autores, la economía de mercado tuvo un componente ético y moral en la obra de Smith. Por eso, como afirma Ricardo Cuevas: "Se sostiene la idea que Smith al fundar la economía política hereda una visión moral para la economía política, el capitalismo y los negocios" (Cuevas, 2009: 53). Al analizar la Teoría de los sentimientos morales en comparación con La riqueza de las naciones, se evidencia que en la obra de Smith sí existe un componente moral que busca el bienestar individual y colectivo. Por eso, es importante desmontar el mito de que el hombre es un ser egoísta y meramente materialista.

\section{Smith y la visión "materialista del hombre"}

La mala e interesada interpretación de las lecturas de Smith, que va de la mano con esa visión del hombre egoísta, también pasa por considerar al hombre como un ser esencialmente materialista. La economía neoclásica planteó la tesis del que el individuo trabajaba según una lógica racional, en la cual impera en todo momento la búsqueda de la maximización de las ganancias. De esa forma surge la idea del "homo económicus" como parte del enfoque neoclásico para definir la acción humana.

Es así como se ha vendido la idea, a partir de las lecturas de los autores clásicos de economía, que el hombre es en esencia un ser materialista. A esas tesis surgieron varios cuestionamientos, sobre todo a partir de estudios antropológicos como el de Godelier (1974), quien ha investigado la existencia de modelos o racionalidades diferentes a la occidental capitalista, se ha desmontado la idea de que el hombre es un ser meramente materialista cuyo único fin es la obtención de ganancias (Godelier, 1974). 
Esas ideas fueron planteadas también por Karl Polanyi en su texto $L a$ gran transformación, donde se hace una crítica del liberalismo económico, precisamente porque se afirma que existen otras formas de organización en ciertas comunidades que no ponen como el centro de su interés la búsqueda de ganancias como se hace en el capitalismo (Polanyi, 1992).

Con esos argumentos se han querido desmontar las tesis del liberalismo. Sin embargo, la visión antropológica del hombre no fue tan materialista en la obra de Smith ni de posteriores economistas. En La Riqueza de las naciones y la Teoría de los sentimientos morales, sobre todo en ese último texto, es evidente cómo no se planteó que el deseo de riqueza debía ser el único objetivo en la vida de los hombres, tal vez ni siquiera el más importante.

De esa manera, en la Teoría de los sentimientos morales expresa Adam Smith que la riqueza no es la única condición para hacer feliz a los hombres, sobre todo cuando se está en situaciones de enfermedad o vejez (Smith, 1978). Bajo esas circunstancias, el hombre puede llegar a "maldecir su ambición" por la búsqueda de cosas que no le proporcionan real satisfacción (Smith, 1978: 120). Después de esos planteamientos, afirma lo vano que puede llegar a significar el poder y la riqueza:

El poder y la riqueza se ven tal como en verdad son: gigantescas y laboriosas máquinas destinadas a proporcionar unas cuantas insignificantes comodidades para el cuerpo... y que, a pesar de toda nuestra solicitud, pueden en todo momento estallar en mil pedazos y aplastar entre sus ruinas a su desdichado poseedor (Smith, 1978: 120).

En ese fragmento se evidencia cómo no se vende una idea meramente materialista de los hombres. Si bien en Los sentimientos morales con respecto a la mano invisible menciona también Smith que el afán del lujo y la inclinación por la belleza de los pudientes no puede evitar ser disfrutada por los demás (Smith, 1978).

Al fin de cuentas la riqueza individual terminaba favoreciendo a la colectividad, el rico al fundar empresas y pagar impuestos da empleo y favorece a la sociedad. No se condena la riqueza en la Teoría de los sentimientos morales, solo se hace ver que no debe constituir el centro principal, o por lo menos no lo único que deben perseguir los individuos a lo largo de sus vidas.

La riqueza, a su vez, debía ser obtenida de forma virtuosa. Siempre se mencionaba en los economistas clásicos la importancia de ocuparse en un oficio útil, de saber administrar los recursos que se obtienen, de no buscar la riqueza fácil sino por medio del esfuerzo productivo y constante.

Por eso tanto énfasis en la manera cómo se obtiene la riqueza, de ahí que en Los sentimientos morales Smith afirma la admiración de la condición de los ricos, pero no solo por lo que consiguen acumular: 
Si examinamos, sin embargo, por qué el espectador singulariza con tanta admiración la condición de los ricos y encumbrados, descubriremos que no obedece tanto a la holgura y placer que se supone disfrutan, cuanto a los innumerables artificiosos y galanos medios de que disponen para obtener esa holgura y placer. En realidad, el espectador no piensa que gocen de mayor felicidad que las demás gentes; se imagina que son poseedores de mayor número de medios para alcanzarla. Y la principal causa de su admiración estriba en la ingeniosa y acertada adaptación de esos medios a la finalidad para que fueron creados (Smith, 1978: 119).

Se evidencia entonces que la riqueza no es la clave de la felicidad, no hay una admiración tanto por lo que consiguen acumular los ricos, sino por las virtudes demostradas para adquirir tales haberes, su manera de conducirse en sociedad y utilizar los medios económicos para lograr la felicidad.

No se trata de condenar la riqueza, ni mucho menos, sino de la importancia de cultivar la virtud y otros valores. Por eso se explica de la estimación que reciben los hombres por dedicarse con esfuerzo a una actividad:

De ahí surge esa alta estimación con que los hombres consideran naturalmente la firme perseverancia en el ejercicio de la frugalidad, industria y consagración, aunque no vaya dirigido a otro fin que la adquisición de fortuna. La denodada firmeza de la persona que así se conduce y que, para obtener una grande, aunque remota ventaja, no solamente renuncia a todo placer presente, sino a soportar los mayores trabajos tanto mentales como corporales, necesariamente impone nuestra aprobación. La perspectiva de su interés y felicidad que parece ordenar su conducta, cuadra exactamente con la idea que naturalmente nos hemos formado de ella (Smith, 1978: 128).

En esa frase de Smith se valora la perseverancia, el trabajo y la disciplina, tanto en la búsqueda de riqueza como en la felicidad personal. Por eso lo valioso de los esfuerzos en el trabajo físico y mental para alcanzar los objetivos. Como ya se afirmó, en La riqueza de las naciones se dio gran preponderancia al trabajo productivo como medio para obtener riqueza (Smith, 1979).

Por tanto, los planteamientos de Smith en la Teoría de los sentimientos morales expresan que su visión del hombre no fue materialista ni mucho menos hedonista, una de las críticas más recurrentemente realizadas al liberalismo en general, por parte principalmente de las corrientes marxistas. El hombre debía buscar la felicidad, la virtud, el interés individual y el colectivo, y la prosperidad general de la sociedad. 


\section{Conclusión}

En este trabajo se ha intentado desmontar varios mitos acerca de las dos obras de Adam Smith que han llevado a muchas malas interpretaciones acerca del funcionamiento de las economías de mercado. La tesis sobre Los sentimientos morales y La riqueza de las naciones deben ser leídas de forma paralela, para establecer la congruencia en las afirmaciones realizadas en ambos textos, que bajo ningún concepto son contradictorios.

La tesis sobre el Estado evidencia cómo Smith, si bien buscaba limitar la acción de las autoridades y evitar la concesión de privilegios, también es cierto que planteó la importancia de mantener una constante fiscalización en materia económica a las empresas, así como regular ciertas actividades.

De igual forma, las tesis de Smith sobre el comercio demuestran cómo este debía promover la concordia entre las naciones. Debía favorecer la competencia para beneficiar a las industrias más eficientes que favorecen también a los consumidores y sociedad en general. La competencia también implica cooperación entre las partes. Los países comercian motivados por el beneficio, pero también hay una dependencia mutua pues toda vez que ambos se benefician.

En cuanto a la visión antropológica del hombre en Smith, se ha argumentado promueve el egoísmo y el materialismo, cuando en realidad, en la obra sobre Los sentimientos morales, es notorio cómo se destacaba el hecho de que se debía busca el bienestar de la sociedad en general. Esto es congruente con lo planteado en La riqueza de las naciones, cuando se afirma que el interés individual y colectivo no son contradictorios.

En la Teoría de los sentimientos morales, Smith afirma también que la felicidad no se logra únicamente a través de riquezas y bienes materiales, la virtud y la preocupación por el bienestar ajeno terminan siendo igual o más importantes. Lamentablemente, las obras de Adam Smith han sido mal interpretadas principalmente por tendencias marxistas, quienes han manipulado sus ideas.

Muchas de sus críticas se enfocan en la ausencia de moralidad del mercado, que promueve la explotación entre los hombres, fomenta la desigualdad y la concentración de la riqueza. Sin embargo, tanto en lo teórico, como se ha demostrado releyendo las obras de Smith, como en lo práctico, al analizar la historia del liberalismo se demuestra que las tesis marxistas no fueron acertadas, aunque lamentablemente todavía tienen muchos seguidores.

La llamada "justicia social redistributiva", el ataque a la propiedad privada y la aplicación de las tesis socialistas solo han demostrado resultados 
deplorables en las naciones donde se han aplicado. Esto lo prueba Stéphane Courtois, en "El libro negro del comunismo" (Courtois, 2010). No es la planificación centralizada de la economía, son las libertades económicas fundamentales las que favorecen la prosperidad de las mayorías, con un Estado que supervisa y regula solo en situaciones particulares y siempre respetando los derechos de los individuos.

\section{Referencias Bibliográficas}

AMIN, Samir. 2009. La crisis. Salir de la crisis del capitalismo o salir del capitalismo en crisis. El viejo Topo. Barcelona, España.

CANTILLON, Richard. 1950. Ensayo sobre la naturaleza del comercio en general. Fondo de Cultura Económica. México DF., México.

COURTOIS, Stéphane. 2010. El libro negro del comunismo: crímenes, terror y represión. Ediciones B. España.

CUEVAS, Ricardo. 2009. "Ética y economía en la obra de Adam Smith: la visión moral del capitalismo" En: Ciencia y Sociedad. Instituto Tecnológico de Santo Domingo República Dominicana. Pp. 52-79.

HAZLITT, Henry. 1961. Los errores de la nueva ciencia económica: un análisis de las falacias keynesianas. Aguilar. España.

FISCHER, Álvaro. 2001. Evolución-el nuevo paradigma: una nueva aproximación a las Ciencias Sociales. Editorial Universitaria. Santiago de Chile, Chile.

GODELIER, Maurice. 1974. Antropología y economía. ¿Es posible la antropología económica? En GODELIER, Maurice. (Coordinador). Antropología y economía. Editorial Anagrama. España. Pp. 279-333.

HOBBES, Thomas. 1980. Leviatán: o la materia, forma y poder de una república eclesiástica y civil. Fondo de Cultura Económica. México DF., México.

LOCKE, John. 1991. Segundo tratado sobre el gobierno civil. Editorial Alianza. Madrid, España.

MUÑOZ, Ángel. 2005. "La mano invisible de Adam Smith o una crítica a la película, «una mente brillante». En: Semestre Económico. Universidad de Medellín, pp. 151-159. 
PENA, José; SÁNCHEZ, José. 2007. "El problema de Smith y la relación entre moral y economía” En: Isegoría. Revista de Filosofía Moral y Política. Universidad de la Coruña. La Coruña, España, pp. 81-103.

POLANYI, Karl. 1992. La gran transformación, Crítica del liberalismo económico. Fondo de Cultura Económica. México DF., México.

POPPER, Karl. 2010. La sociedad abierta y sus enemigos. Paidos Ibérica. Barcelona, España.

ROTHBARD, Murray. 2006. Por una economía con sentido. Ludwig Von Mises Institute Auburn. Alabama, EUA.

SMITH, Adam. 1979. Investigación sobre la naturaleza y causas de la riqueza de las naciones. Edición de Edwin Cannan y una introducción de Max Lerner. Fondo de Cultura Económica. México DF., México.

SMITH, Adam. 1978. Teoría de los sentimientos morales. Fondo de Cultura Económica. México DF., México.

STIGLITZ, Joseph. 2007. Comercio justo para todos. Taurus. Barcelona, España.

VON MISES, Ludwig. 1986. La acción humana. Tratado de economía. Unión Editorial. Madrid, España. 

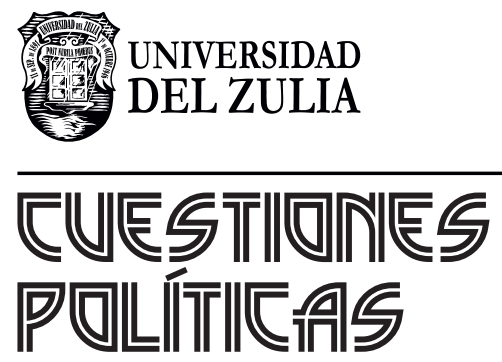

Vol. $37 \mathrm{~N}^{\circ} 64$

Esta revista fue editada en formato digital y publicada en junio de 2020, por el Fondo Editorial Serbiluz, Universidad del Zulia. Maracaibo-Venezuela 